\title{
Conservative and Surgical Treatment of Talar Fractures: A Systematic Review and Meta-Analysis on Clinical Outcomes and Complications
}

\author{
Babak Saravi ${ }^{1,2, * \mathbb{D}}$, Gernot Lang ${ }^{1,2}{ }^{\text {, Robert Ruff }}{ }^{1}$, Hagen Schmal ${ }^{1}$ (D) Norbert Südkamp ${ }^{1}$, Sara Ülkümen ${ }^{1,2}$ \\ and Jörn Zwingmann ${ }^{1,3}$
}

check for updates

Citation: Saravi, B.; Lang, G.; Ruff, R.; Schmal, H.; Südkamp, N.; Ülkümen, S.; Zwingmann, J. Conservative and Surgical Treatment of Talar Fractures: A Systematic Review and Meta-Analysis on Clinical Outcomes and Complications. Int. J. Environ. Res. Public Health 2021, 18, 8274. https://doi.org/10.3390/ ijerph18168274

Academic Editor: Jaeho Cho

Received: 2 July 2021

Accepted: 2 August 2021

Published: 4 August 2021

Publisher's Note: MDPI stays neutral with regard to jurisdictional claims in published maps and institutional affiliations.

Copyright: (c) 2021 by the authors Licensee MDPI, Basel, Switzerland. This article is an open access article distributed under the terms and conditions of the Creative Commons Attribution (CC BY) license (https:/ / creativecommons.org/licenses/by/ $4.0 /)$.
1 Department of Orthopedics and Trauma Surgery, Medical Center, Faculty of Medicine, Albert-Ludwigs-University of Freiburg, 79106 Freiburg, Germany; gernot.lang@rkk-klinikum.de (G.L.); robert.ruff@diak-fr.de (R.R.); hagen.schmal@uniklinik-freiburg.de (H.S.); norbert.suedkamp@uniklinik-freiburg.de (N.S.); sara.uelkuemen@jupiter.uni-freiburg.de (S.Ü.); Joern.Zwingmann@oberschwabenklinik.de (J.Z.)

2 Department of Spine Surgery, Loretto-Krankenhaus Freiburg, 79100 Freiburg, Germany

3 Department of Orthopedics and Trauma Surgery, St. Elisabeth Hospital Ravensburg, 88212 Ravensburg, Germany

* Correspondence: babak.saravi@jupiter.uni-freiburg.de
Abstract: The integrity of the talus is crucial for the physiologic function of the feet. The present study sought to summarize the available evidence on clinical outcomes and complications following conservative and surgical treatment of talar fractures. We systematically searched Medline via OVID to find relevant studies with a follow-up of at least six months. Hereafter, the success and complication rates were extracted and analyzed in a random effects proportion meta-analysis. Complications were defined as avascular bone necrosis (AVN) and posttraumatic osteoarthritis (OA). Additionally, a subgroup analysis was performed for fracture localization (talar neck fractures (TN) and combined talar body/neck fractures (TN/TB)) and severity of the fracture. The quality of the included studies was assessed utilizing the Coleman Methodology Score (CMS). A total of 29 retrospective studies, including 987 fractures with a mean follow-up of 49.9 months, were examined. Success rates were $62 \%, 60 \%$, and $50 \%$ for pooled fractures, $\mathrm{TN}$, and $\mathrm{TN} / \mathrm{TB}$, respectively. The overall complication rate for AVN was $25 \%$. The rate was higher for TN (43\%) than TN/TB (25\%). Talar fractures revealed a $43 \%$ posttraumatic osteoarthritis (OA) rate in our meta-analysis. Success rates showed an association with fracture severity, and were generally low in complex multi-fragmentary fractures. The mean CMS was 34.3 (range: 19-47), indicating a moderate methodological quality of the studies. The present systematic review on clinical outcomes of patients undergoing conservative or surgical treatment for talar fractures reveals a lack of reliable prospective evidence. Talar fractures are associated with relatively poor postoperative outcomes, high rates of AVN, and posttraumatic osteoarthritis. Poor outcomes revealed a positive association with fracture severity. Prospective studies investigating predictors for treatment success and/or failure are urgently needed to improve the overall quality of life and function of patients undergoing surgical treatment due to talar fractures.

Keywords: talus; ankle fractures; ankle injuries; osteoarthritis; osteonecrosis; systematic review

\section{Introduction}

Talar fractures account for $0.3 \%$ of all fractures and $3.4 \%$ of foot fractures $[1,2]$. The integrity of the talus is crucial to the normal function of the ankle, subtalar, and transverse tarsal joints. Injuries to the head, neck, or body of the talus can disrupt the physiologic movement of these joints, potentially leading to chronic pain, loss of motion, and deformity. Typical findings after incorrectly healed talus fractures are axial deviations, in particular varus malalignment, posttraumatic osteoarthritis of the upper and lower ankle joints, symptomatic pseudarthrosis, impingement of the posterior tibial tendon or tarsal tunnel 
syndrome due to bony prominences, and, finally, the collapse of the talar body [3]. One of the most common causes of central talar fractures is a fall from a great height [1]. The typical trauma mechanism of talar neck fractures (contributing to more than $50 \%$ of all talar fractures) involves forced dorsiflexion of the foot combined with extensive axial forces. Consequently, the neck of the talus is sheared between the anterior edge of the tibia and the sustentaculum tali. In contrast, forced plantar flexion combined with a rotational component at the time of violence is held responsible for talar body fractures (around 20\% of all talar injuries) [4]. The rare talar head fractures (less than $10 \%$ of all talar fractures) usually occur when the midtarsal (Chopart) joint is involved, and are caused by forced abduction or adduction of the forefoot with simultaneous rotation of the rear foot [5]. Notably, $13-15 \%$ of all talar fractures are open fractures [6]. Concomitant injuries are found in nearly half of all talar fractures [4,7]. Severe soft tissue damage occurs in approximately $15 \%$ of cases [6]. Additional regional injuries include malleolar fractures (in up to $44 \%$ of fracture cases), injuries to the calcaneus (in $11-18 \%$ of fracture cases), and concomitant metatarsal fractures (in up to $18 \%$ of fracture cases) [8,9].

The talar body is mainly supplied by an anastomosis between the canalis tarsi artery and the sinus tarsi artery. The vessels enter the talar body at the level of the talar neck and run from distal to proximal. If this anastomosis ruptures due to dislocated fractures of the talar neck, the risk of bone necrosis is significantly increased [10]. Additionally, the deltoid branch is discussed as an important vessel that revascularizes the talus from the medial side after fractures and should, therefore, be spared in medial surgical access [10-12]. The extensive cartilaginous surface of the talus affects blood supply and leads to a high risk of posttraumatic damage, such as avascular bone necrosis (AVN) and posttraumatic osteoarthritis [11]. AVN is reported to occur in up to $50 \%$ of central fractures and dislocations [13]. Although the necrosis rate is reported to vary considerably, there seems to be a correlation with the initial degree of dislocation. AVN is found in $0-24 \%$ of Hawkins type I fractures, whereas 33-100\% occur in Hawkins type III and IV fractures [11,14]. Nondisplaced fractures of the talar body (Marti type II) are associated with AVN in 5-44\% of cases, and displaced talar body fractures (Marti types III and IV) can result in AVN in up to $50 \%$ of patients [15]. With open fractures, the risk of AVN appears to be increased [16,17].

The rates for posttraumatic osteoarthritis after talar neck and body fractures vary between $16 \%$ and $100 \%[16,18]$. One possible explanation could be the lack of standardized diagnostic criteria and different follow-up periods in the literature. The rate of posttraumatic osteoarthritis seems to increase over time. However, not all cases become symptomatic. A clear link between the severity of the fracture and AVN could not be established to date $[17,19]$. A malalignment of the talar neck, which leads to significant load-bearing properties in the ankle and subtalar joints, or remaining unevenness in the joint surface, may cause poorer clinical results. Therefore, these conditions should be considered as pre-arthritic triggers [16,20-22]. Other reported postoperative complications are dermal necrosis $(11 \%)$ and infections $(3-8 \%)[6,16,19,23]$. Septic necrosis of the talar body is a severe complication, not infrequently requiring partial or total removal of the talus $[24,25]$.

The general goal of therapy is early restoration of the anatomical situation. The congruence of the ankle and subtalar joints should be restored promptly by optimizing the remaining blood supply to reduce the risk of avascular necrosis [2]. Non-displaced fractures of the talar body can be treated conservatively with a lower leg orthosis up to 16 weeks [6,14,26-29]. However, osteoarthritis of the ankle joint and/or lower ankle joint can also occur in such low-grade fractures [1]. Surgical repositions and fixations are required for high-graded fractures and dislocations. Nevertheless, early mobilization and physiotherapy are recommended for functional rehabilitation. Fractures of the talar head have a more favorable prognosis than fractures of the body or neck due to the limited blood supply $[1,30]$. Moreover, therapeutical outcomes vary widely, and are frequently related to the degree of initial fracture displacement. Minimally displaced fractures can be hard to diagnose and might miss early treatments, followed by poor outcomes [31]. Peripheral and 
non-dislocated central talar fractures are often misdiagnosed as distortions in the upper or lower ankle [32].

There is controversy regarding the optimal therapeutic approaches for talus fractures. Specifically, the rate of posttraumatic osteoarthritis, secondary interventions, avascular necrosis, and the effect of the interval until surgical treatment on the factors mentioned need to be further explored $[33,34]$. Clinical outcomes depend on the initial degree of dislocation, joint involvement, and soft tissue damage. However, clinical reports vary considerably. Results with good and excellent clinical outcomes for talar neck fractures range from $40-100 \%, 32-80 \%$, and $15-55 \%$ for Hawkins I fractures, Hawkins II fractures, and Hawkins III fractures, respectively. These high variation ranges may be caused by different distributions of concomitant injuries [32]. In the most extensive study to-date on talar body fractures, 39 of 66 patients (59\%) complained of temporary or persistent symptoms [35]. Furthermore, the authors reported posttraumatic osteoarthritis in eight out of nine $(88 \%)$ conservatively treated fractures.

Available reviews on this topic focused solely on talar neck fractures $[33,36,37]$ or talar head fractures [38]. Considering the variability in the literature and the development of new therapeutic options, an updated comprehensive review focusing on both talar neck and body fractures that summarizes the current status of clinical outcomes of talar fractures is warranted. The inclusion of both conservative and surgical treatments, such as multiplanar external fixation, open articular bony reduction, and internal fixation, as well as non-operative treatments, such as casting, along with the inclusion of all studies regardless of publication year, further allows the evaluation of the outcome of the therapeutical approaches over time, considering that the therapeutical strategies might have changed and will be the fundament of the present review.

The present systematic review with a meta-analysis sought to summarize the available evidence on clinical outcomes and complications following conservative and surgical treatment of talar fractures.

\section{Materials and Methods}

\subsection{Study Selection}

The present systematic review was performed in accordance with the Preferred Reporting Items for Systematic Reviews and Meta-Analyses (PRISMA) statement [39]. The literature was searched from inception up to 2020. The targets of the structured search approach were prospective and retrospective studies focusing on clinical outcomes of talar fractures. We applied language restrictions to obtain studies published in English or German. Additionally, a combined medical subject heading (MeSH) and free-text term search in Medline (via OVID), including the MeSH terms "Talus/", "Tarsal bones/", "Ankle Joint/", and "Foot injuries/", was performed. Truncations were used to retrieve all forms of the search terms. A combination of search terms was performed by the Boolean operators AND and OR (Table 1).

We included all clinical studies in humans with prospective and retrospective study designs, assessing outcomes of non-operative and operative talar fractures with a follow-up of at least six months. After initially including all relevant studies, exclusion criteria were applied as follows:

1. Reviews/meta-analysis

2. Case reports

3. Fractures not involving the talar body, neck, or head

4. Non-human studies

5. Non-German or English studies

6. Follow-up under six months 
Table 1. Search strategy.

\begin{tabular}{cc}
\hline Search Step & Search Terms and Operators \\
\hline 1 & Talus/ \\
2 & Tarsal bones/ \\
3 & exp Tarsal joints/ \\
4 & Ankle Joint/ \\
5 & Foot injuries/ \\
6 & 1 or 2 or 3 or 4 or 5 \\
7 & Fractures, Bone/ \\
8 & 6 and 7 \\
9 & talus.tw./ \\
10 & 8 and 9 \\
11 & fracture $*$ tw./ \\
12 & 10 and 11 \\
13 & exp animals $/$ not humans/ \\
14 & 12 not 13 \\
\hline
\end{tabular}

* Word truncation.

\subsection{Data Extraction and Organization}

The selection of studies was performed by two independent reviewers (R.R. and J.Z.) in a two-step process. Titles and abstracts were first screened for relevance, followed by a full-text analysis. Data extraction was based on a standardized data extraction form that included all relevant information:

1. Name of the author(s), name of the journal, year of publication, study type, level of evidence

2. Fracture localization (neck, body, head)

3. Number of patients and the examined talus fractures stratified by fracture location

4. Epidemiological data (age, sex)

5. Follow-up in months (average and range)

6. Number of patients in follow-up/dropouts

7. Number of patients with open fractures

8. Number of patients treated surgically

9. Time until surgery in days

10. Postoperative readjustment of the fractures (postoperative reduction)

11. Poor or no fracture healing (malunion/non-union)

12. Type of surgical treatment

13. Frequency of early complications

14. Fracture classification

15. Number of patients with the respective degree of fracture severity, according to classification

16. Treatment result (result of the specific outcome scores)

17. Complications (AVN, osteoarthritis)

18. Frequency of joint stiffening (arthrodesis)

The results of the specific outcome scores were extracted, and the number of patients with excellent, good, moderate, and bad results was noted. Total numbers of patients with AVN and posttraumatic osteoarthritis signs were extracted regardless of severity. The number of patients with excellent and good results according to the individual utilized outcome scores were then pooled to determine the proportion of successful interventions in each cohort. The proportions of patients with AVN and posttraumatic osteoarthritis were noted to determine the proportion of complications in each cohort.

\subsection{Assessment of the Methodological Quality of Included Studies}

The methodological quality of included studies was assessed with the Coleman Methodology Score (CMS) [40]. The Coleman Methodology Score is a helpful tool for quantifying the quality of clinical studies. Ten items are used to evaluate the methodology 
of a study. The CMS consists of two parts (A and B) (Table 2). The subcategories in part A are assessed individually (maximum 60 points). In part B, multiple points can be awarded per subgroup (maximum 40 points). The sum of both parts results in a value between 0 (worst methodological quality) and 100 (best methodological quality). Furthermore, we determined the level of evidence for each of the included studies [41]. The following evidence levels were applied: level 1, randomized controlled study; level 2, prospective cohort study; level 3, case control study; level 4, case series; and level 5, expert opinion.

Table 2. Coleman Methodology Score.

\begin{tabular}{|c|c|c|c|}
\hline Step & Criterion & Subcriterion & Score \\
\hline \multicolumn{4}{|c|}{ Coleman Methodology Score Part A (Max. 60 points) } \\
\hline \multirow{4}{*}{1.} & \multirow{4}{*}{ Study size } & $>60$ & 10 \\
\hline & & $41-60$ & 7 \\
\hline & & $20-40$ & 4 \\
\hline & & $<20$ or no information & 0 \\
\hline \multirow{3}{*}{2.} & \multirow{3}{*}{ Mean follow-up (in months) } & $>24$ & 5 \\
\hline & & $12-24$ & 2 \\
\hline & & $<12$, no information or unclear & 0 \\
\hline \multirow{3}{*}{3.} & \multirow{3}{*}{$\begin{array}{l}\text { Number of different surgeries } \\
\text { performed for each outcome included }\end{array}$} & Only one procedure performed & 10 \\
\hline & & $>1$ procedure performed, but used in at least $90 \%$ of patients & 7 \\
\hline & & $\begin{array}{l}\text { No information, unclear, or use of only one procedure in less than } 90 \% \text { of } \\
\text { the patients included }\end{array}$ & 0 \\
\hline \multirow{3}{*}{4.} & \multirow{3}{*}{ Type of study } & Randomized controlled & 15 \\
\hline & & Prospective cohort & 10 \\
\hline & & Retrospective cohort & 0 \\
\hline \multirow{3}{*}{5.} & \multirow{3}{*}{$\begin{array}{l}\text { Diagnostic certainty (use of } \\
\text { sonography, MRI, or histopathology } \\
\text { to confirm the diagnosis) }\end{array}$} & $100 \%$ of patients & 5 \\
\hline & & $>80 \%$ of patients & 3 \\
\hline & & $<80 \%$ of patients & 0 \\
\hline \multirow{3}{*}{6.} & \multirow{3}{*}{$\begin{array}{l}\text { Description of the surgical therapy } \\
\text { procedure }\end{array}$} & Adequate (surgical technique mentioned and described in detail) & 5 \\
\hline & & Moderate (surgical technique mentioned, but no detailed description) & 3 \\
\hline & & Inadequate (surgical technique not mentioned) or unclear & 0 \\
\hline \multirow{3}{*}{7.} & \multirow{3}{*}{$\begin{array}{l}\text { Description of postoperative } \\
\text { rehabilitation }\end{array}$} & Well-described and $>80 \%$ of patients compliant to therapy & 10 \\
\hline & & Well-described and $60-80 \%$ of patients compliant to therapy & 5 \\
\hline & & No protocol described or $<60 \%$ of patients compliant to therapy & 0 \\
\hline \multicolumn{4}{|c|}{ Coleman Methodology Score Part B (Max. 40 points) } \\
\hline \multirow{4}{*}{1.} & \multirow{4}{*}{$\begin{array}{l}\text { Outcome criteria ( } 0 \text { points are } \\
\text { awarded in this section if the outcome } \\
\text { criteria are not defined precisely) }\end{array}$} & Clearly defined measures for outcome & 2 \\
\hline & & Follow-up examination and evaluation of the outcome clearly defined & 2 \\
\hline & & Use of outcome criteria with good reliability & 3 \\
\hline & & Use of outcome criteria with good sensitivity & 3 \\
\hline \multirow{4}{*}{2.} & \multirow{4}{*}{ Procedure for outcome-assessment } & Patients called in for a follow-up examination & 5 \\
\hline & & Examiner independent of the surgeon & 4 \\
\hline & & Assessment is documented in writing & 3 \\
\hline & & Completion of the assessment with minimal involvement of the examiner & 3 \\
\hline \multirow{4}{*}{3.} & \multirow{4}{*}{ Description of patient selection } & Selection criteria specified and unbiased & 5 \\
\hline & & Recruitment rate $>80 \%$ & 5 \\
\hline & & Recruitment rate $<80 \%$ & 3 \\
\hline & & Exclusion criteria clearly described or $100 \%$ recruitment rate & 5 \\
\hline
\end{tabular}

\subsection{Statistics}

We included all studies matching our predefined inclusion and exclusion criteria in the qualitative synthesis results. In the first step, the studies were stratified into subgroups depending on their fracture localization. Extracted outcome scores were used to determine the proportion of successful interventions and complications within each cohort. Hereafter, 
we performed a meta-analysis of each subgroup to assess and compare clinical outcomes of studies within each subgroup. A proportion meta-analysis using a random effects model considering the weights of individual studies for outcome calculations was performed with the meta package in R (R studios, version 3.6.2). Heterogeneity was assessed with $I^{2}$ statistics. Values of $I^{2}$ more than $25 \%, 50 \%$, and $75 \%$ were defined as low, moderate, and high heterogeneity, respectively [42]. Meta-analyses and their graphic representation using forest plots were implemented using the metaprop and forest commands [43].

\section{Results}

\subsection{Study Characteristics and Qualitative Outcome Assessment}

A total of 581 studies were identified through the database search. After screening the abstracts, 98 studies remained for full-text analysis. Overall, $n=552$ studies were excluded, mainly because the predefined study design criteria were not fulfilled $(n=155)$ or the fracture localization was not of interest $(n=64)$. Finally, 29 publications matching the eligibility criteria were included in the qualitative synthesis (Figure 1) [4,6,16-18,23,28,29,35,44-63]. All of these studies provided outcomes with sufficient extractable quantitative data, and could be included in the quantitative synthesis.
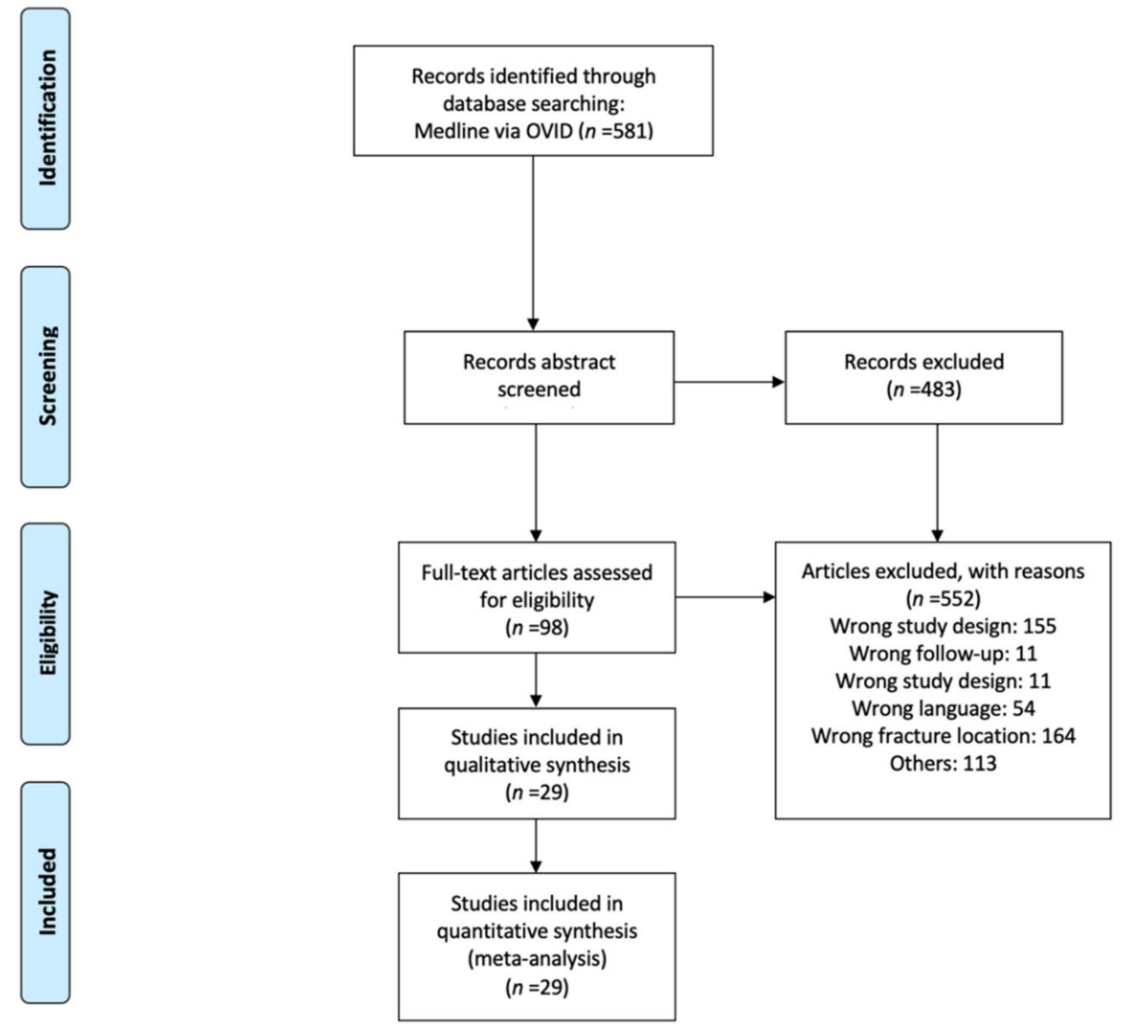

Figure 1. PRISMA flow diagram of the selection process.

The 29 included studies included 1193 talar neck, body, and head fractures. On average, a study subgroup consisted of 41.1 (6-137) talar neck, body, and/or head fractures. The mean age across all study groups was $33.35 \pm 5.5$ years. At the time of treatment, the youngest patient was seven, and the oldest was 83 years old. The gender distribution could be determined for 27 studies, including 1050 patients $(88 \%)$. In these studies, $767(73 \%)$ patients were male and $283(27 \%)$ were female. A mean follow-up period of 50 months could be determined from the data provided in 27 studies. The included studies were published between 1967 and 2019. Characteristics of the included studies are shown in Table 3. 
Table 3. Study characteristics.

\begin{tabular}{|c|c|c|c|c|c|c|c|c|}
\hline Author and Year & $\begin{array}{l}\text { Study } \\
\text { Design }\end{array}$ & Localization & NoFx & NoSFx & $\begin{array}{l}\text { Conservative or } \\
\text { Closed Fixation }\end{array}$ & ORIF & $\begin{array}{c}\text { External } \\
\text { Restraint }\end{array}$ & $\begin{array}{l}\text { Other Primary } \\
\text { Intervention }\end{array}$ \\
\hline Liu 2019 & Retrospective & $\mathrm{TN}, \mathrm{TB}$ & 26 & 26 & & & & 23 \\
\hline Liu 2017 & Retrospective & TN & 22 & 21 & & 21 & & \\
\hline Xue 2014 & Retrospective & $\mathrm{TN}$ & 31 & 22 & 9 & 22 & & \\
\hline Chen 2014 & Retrospective & $\mathrm{TN}$ & 44 & 38 & & 38 & & \\
\hline Ohl 2011 & Retrospective & $\mathrm{TN}, \mathrm{TB}$ & 20 & 20 & & 20 & & \\
\hline Tang 2010 & Retrospective & TN & 9 & 9 & & & & 9 \\
\hline Pogliacomi 2009 & Retrospective & $\mathrm{TN}, \mathrm{TB}, \mathrm{TH}$ & 16 & 13 & & & & NR \\
\hline Vallier 2004 & Retrospective & TN, TB & 56 & 56 & & 37 & & 19 \\
\hline Lindvall 2004 & Retrospective & $\mathrm{TN}, \mathrm{TB}$ & 26 & 26 & NR & 7 & & \\
\hline Schulze 2002 & Retrospective & $\mathrm{TN}, \mathrm{TB}$ & 80 & 80 & & 67 & 1 & 12 \\
\hline Besch 2002 & Retrospective & $\mathrm{TN}, \mathrm{TB}$ & 23 & 23 & & 22 & 5 & 4 \\
\hline Elgafy 2000 & Retrospective & $\mathrm{TN}, \mathrm{TB}$ & 60 & 48 & & & & \\
\hline Kankare 1998 & Retrospective & $\mathrm{TN}, \mathrm{TB}$ & 6 & 6 & & 8 & & \\
\hline Schwarz 1997 & Retrospective & TN, TB & 19 & 9 & & 5 & & \\
\hline Frawley 1995 & Retrospective & $\mathrm{TN}, \mathrm{TB}, \mathrm{TH}$ & 28 & 20 & & 20 & & \\
\hline Freund 1988 & Retrospective & TN & 7 & 7 & 2 & 3 & & 2 \\
\hline Szyszkowitz 1985 & Retrospective & $\mathrm{TN}, \mathrm{TB}$ & 85 & 85 & 23 & 54 & & 8 \\
\hline Santavirta 1984 & Retrospective & $\mathrm{TN}, \mathrm{TB}, \mathrm{TH}$ & 35 & 11 & & 7 & & 4 \\
\hline Penny 1980 & Retrospective & $\mathrm{TN}$ & 40 & 30 & & NR & & 9 \\
\hline Lemaire 1980 & Retrospective & TH & 7 & 7 & & 7 & & \\
\hline Zifko 1979 & Retrospective & $\mathrm{TN}, \mathrm{TB}, \mathrm{TH}$ & 137 & 24 & NR & NR & & NR \\
\hline Canale 1978 & Retrospective & TN & 71 & 57 & NR & 25 & & 11 \\
\hline Lorentzen 1977 E & Retrospective & $\mathrm{TN}$ & 123 & 20 & 33 & 14 & & 2 \\
\hline Peterson 1977 & Retrospective & $\mathrm{TN}$ & 46 & 29 & 14 & 7 & & 8 \\
\hline Sneppen 1977 & Retrospective & $\mathrm{TN}$ & 51 & 9 & & 9 & & \\
\hline Gilquist 1974 & Retrospective & $\mathrm{TN}, \mathrm{TB}$ & 28 & 13 & 9 & 13 & & \\
\hline Pantazopoulos 1974 & Retrospective & $\mathrm{TN}$ & 20 & 11 & 5 & 10 & & 1 \\
\hline Hawkins 1970 & Retrospective & $\mathrm{TN}$ & 55 & 34 & 24 & 22 & & \\
\hline Herwig 1967 & Retrospective & $\mathrm{TN}, \mathrm{TB}, \mathrm{TH}$ & 22 & 13 & & 9 & & 4 \\
\hline
\end{tabular}

NoFx: number of fractures; NoSFx: number of surgically treated fractures; ORIF: open fixation or open reduction with internal fixation; TN: talar neck; TB: talar body; TH: talar head; NR: not reported.

Eight studies examined talar neck and corpus fractures [16-18,44,48,50,52,54,59], whereas eleven studies solely focused on talar neck fractures $[4,6,28,29,47,51,52,55,56,61,62]$. A more detailed subgroup analysis was carried out in 17/29 included studies. Consequently, fractures were classified according to their location and severity, and their respective clinical outcome was examined. Talar neck/talar body fractures and talar neck fracture subgroups were formed to investigate AVN and posttraumatic OA as complications. Another subgroup analysis was performed for patients suffering osteoarthritis with subsequent arthrodesis as a follow-up intervention.

A follow-up examination was carried out for 987 fractures (82\%). In 325/987 (32\%) fractures, the result was judged excellent; in 257/987 (26\%) fractures, the result was good, and $216 / 987(21 \%)$ of the fractures showed moderate results in the clinical follow-up examination. A total of 188/987 (19\%) fractures showed unsatisfactory results in the follow-up examination. All 29 included studies provided information on complications. Complications were found in $741 / 1184(62 \%)$ cases. Of these, 314 cases were OA, requiring $n=81$ arthrodesis and $n=18$ subtalar fusions as follow-up interventions.

A total of $994 / 1184$ patients from $26 / 29$ studies could be examined depending on the fracture location. From these, 803/994 (80\%) had talar neck fractures, 153/994 (15\%) talar body fractures, and 40/994 (5\%) talar head fractures. Moreover, 151/919 (16\%) open fractures were found in 20/29 included studies providing detailed information about the fractures and concomitant injuries.

In 17/29 studies, fractures were classified according to location and severity of the fracture. Hawkins 1 and Hawkins 2 fractures were seen in 219 patients, whereas Hawkins 3 and 4 were seen in 133 patients. Furthermore, $n=29$ and $n=31$ fractures were judged as Marti/Weber $1+2$ and $3+4$ grade, respectively. For Szyszkowitz classification $1+2$ and $3+4$, the respective numbers were $n=36$ and $n=59$. 


\subsection{Assessment of the Methodological Quality}

All included studies were retrospective studies. The majority of studies were case series corresponding to level 4 evidence. The mean CMS A was 23.9 (range: 9-36), whereas the mean CMS B was 10.4 (range: 8-13). The corresponding total mean CMS was 34.3 (range: 19-4), indicating a generally moderate methodological quality of the included studies (Table 4).

Table 4. Assessment of the methodological quality of included studies.

\begin{tabular}{ccccccc}
\hline Author & Study Year & $\begin{array}{c}\text { Study } \\
\text { Design }\end{array}$ & $\begin{array}{c}\text { Level of } \\
\text { Evidence }\end{array}$ & CMS A & CMS B & CMS Total \\
\hline Liu & 2019 & Retrospective & 4 & 21 & 12 & 33 \\
Liu & 2017 & Retrospective & 4 & 29 & 12 & 41 \\
Xue & 2014 & Retrospective & 4 & 34 & 13 & 47 \\
Chen & 2014 & Retrospective & 3 & 24 & 12 & 36 \\
Ohl & 2011 & Retrospective & 4 & 36 & 11 & 47 \\
Tang & 2010 & Retrospective & 4 & 10 & 9 & 19 \\
Pogliacomi & 2009 & Retrospective & 4 & 17 & 10 & 27 \\
Vallier & 2004 & Retrospective & 4 & 30 & 8 & 38 \\
Lindvall & 2004 & Retrospective & 4 & 24 & 12 & 36 \\
Schulze & 2002 & Retrospective & 4 & 30 & 12 & 42 \\
Besch & 2002 & Retrospective & 3 & 24 & 10 & 34 \\
Elgafy & 2000 & Retrospective & 4 & 25 & 10 & 35 \\
Kankare & 1998 & Retrospective & 4 & 28 & 10 & 38 \\
Schwarz & 1997 & Retrospective & 4 & 26 & 10 & 36 \\
Frawley & 1995 & Retrospective & 4 & 24 & 10 & 34 \\
Freund & 1988 & Retrospective & 4 & 20 & 10 & 30 \\
Szyszkowitz & 1985 & Retrospective & 4 & 27 & 10 & 37 \\
Santavirta & 1984 & Retrospective & 4 & 9 & 10 & 19 \\
Penny & 1980 & Retrospective & 4 & 14 & 10 & 24 \\
Lemaire & 1980 & Retrospective & 4 & 22 & 10 & 32 \\
Zifko & 1979 & Retrospective & 4 & 25 & 10 & 35 \\
Canale & 1978 & Retrospective & 4 & 25 & 10 & 35 \\
Lorentzen & 1977 & Retrospective & 4 & 22 & 10 & 32 \\
Peterson & 1977 & Retrospective & 4 & 27 & 10 & 37 \\
Sneppen & 1977 & Retrospective & 4 & 22 & 10 & 32 \\
Gilquist & 1974 & Retrospective & 4 & 29 & 10 & 39 \\
Pantazopoulos & 1974 & Retrospective & 4 & 24 & 10 & 34 \\
Hawkins & 1970 & Retrospective & 4 & 22 & 10 & 32 \\
Herwig & 1967 & Retrospective & 4 & 24 & 10 & 34 \\
\hline & & & & & \\
& & & & & \\
\end{tabular}

\subsection{Quantitative Analysis}

\subsubsection{Success Rates}

The success rate (i.e., good or excellent outcome) for pooled fractures regardless of localization was $62 \%$ (Figure 2). A subgroup analysis based on the fracture location resulted in a $60 \%$ success rate for TN fractures and a 50\% success rate for TN/TB fractures. However, statistical heterogeneity was high, with $I^{2}$ values of $91 \%, 85 \%$, and $92 \%$ for pooled fractures, $\mathrm{TN}$, and $\mathrm{TN} / \mathrm{TB}$, respectively.

Twelve studies were considered in the TN fracture subgroup, including a total of 377 fractures. Overall, $60 \%$ of the examined fractures had a good or excellent outcome in the follow-up examination, regardless of the fracture severity (Figure 3).

The subgroup TN/TB fractures included $n=246$ fractures with a $48 \%$ success rate, indicating a good or excellent outcome in nearly half of the patients (Figure 4). 


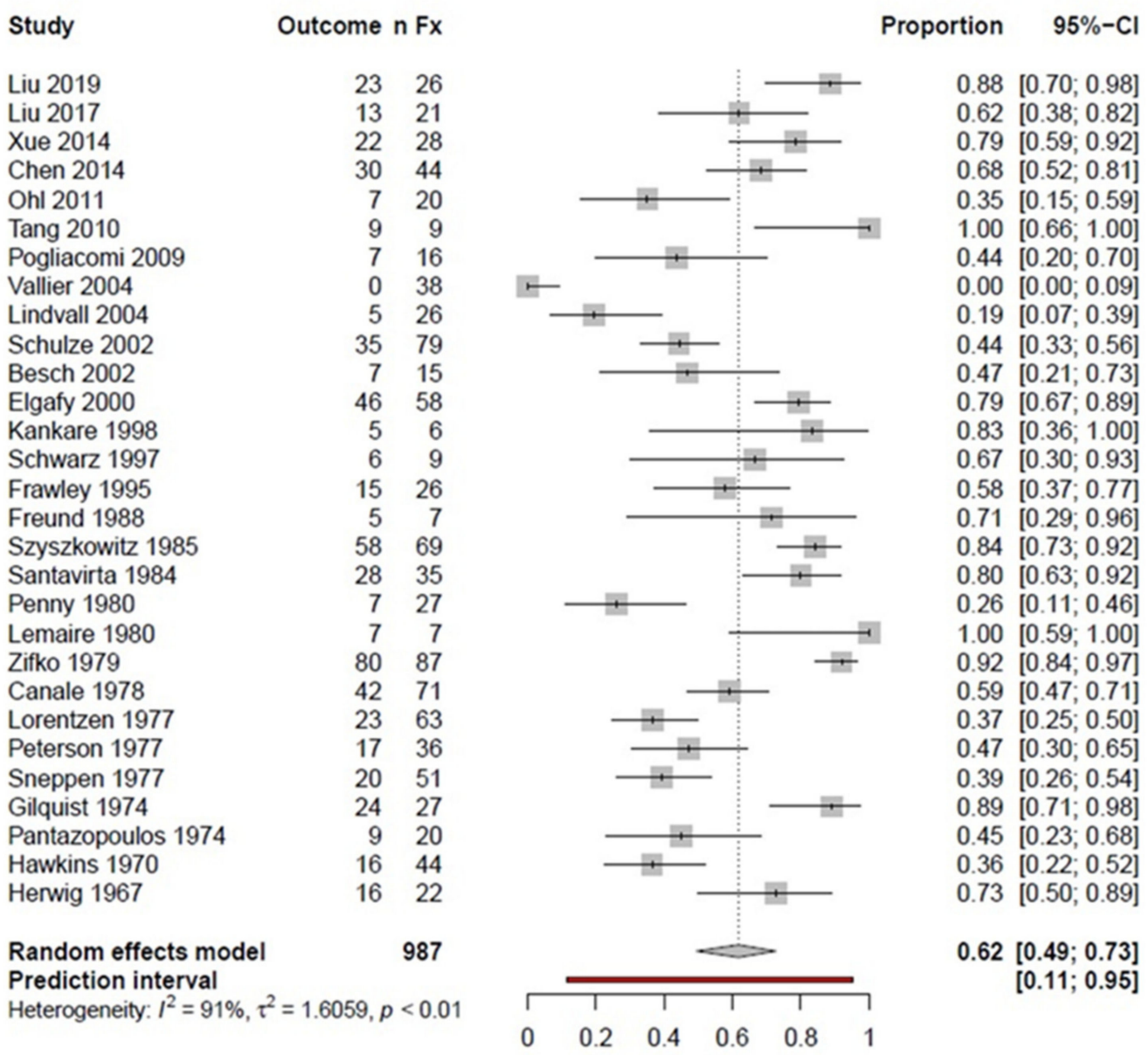

Figure 2. Forest plot showing the proportion meta-analysis of pooled talar fractures; $n \mathrm{Fx}$ : number of fractures; CI: confidence interval.

$\begin{array}{lrr}\text { Study } & \text { Outcome } & \text { n Fx } \\ \text { Liu 2017 } & 13 & 21 \\ \text { Xue 2014 } & 22 & 28 \\ \text { Chen 2014 } & 30 & 44 \\ \text { Tang 2010 } & 9 & 9 \\ \text { Freund 1988 } & 5 & 7 \\ \text { Penny 1980 } & 9 & 27 \\ \text { Lemaire 1980 } & 7 & 7 \\ \text { Canale 1978 } & 42 & 71 \\ \text { Lorentzen 1977 } & 23 & 63 \\ \text { Peterson 1977 } & 17 & 36 \\ \text { Pantazopoulos 1974 } & 9 & 20 \\ \text { Hawkins 1970 } & 16 & 44 \\ & & \\ \text { Random effects model } & & 377 \\ \text { Prediction interval } & \\ \text { Heterogeneity: } I^{2}=80 \%, \tau^{2}=0.6170, p<0.01\end{array}$

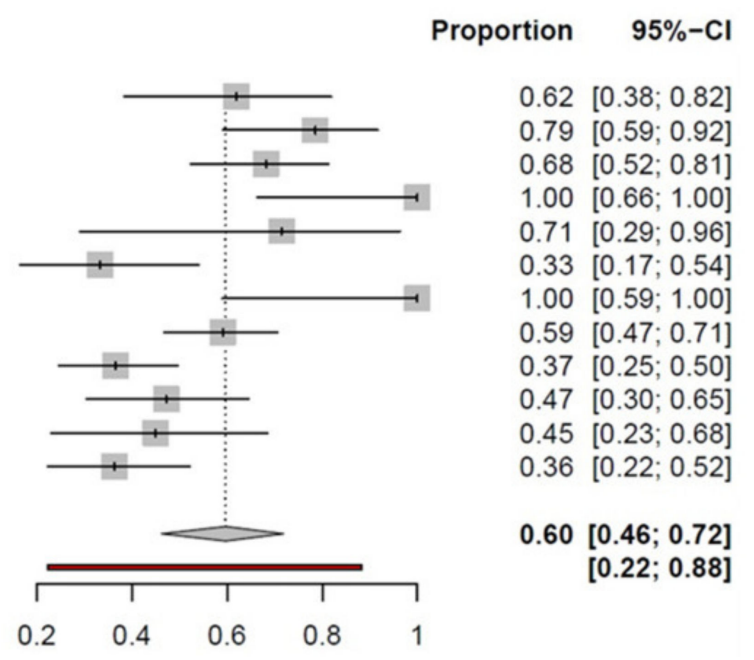

Figure 3. Forest plot showing the proportion meta-analysis of talar neck fractures; $n$ Fx: number of fractures; CI: confidence interval.

A subgroup analysis was carried out according to fracture location and severity. The fractures classified according to Hawkins $1(n=69)$ showed a $65 \%$ success rate. The heterogeneity in the subgroup was judged low, with $I^{2}=27 \%$. Hawkins 2 fractures $(n=150)$ revealed a success rate of $48 \%$, with a moderate heterogeneity of $I^{2}=47 \%$. Similarly, Hawkins 3 fractures $(n=124)$ comprised success rates of $40 \%$, with a moderate 
heterogeneity of $I^{2}=48 \%$. In contrast, Hawkins $4(n=9)$ fractures were associated with low success rates of $25 \%$, with no observable heterogeneity $\left(I^{2}=0 \%\right)$.

$\begin{array}{lrr}\text { Study } & \text { Outcome } & \text { n Fx } \\ \text { Liu 2019 } & 23 & 26 \\ \text { Ohl 2011 } & 7 & 20 \\ \text { Vallier 2004 } & 0 & 38 \\ \text { Lindvall 2004 } & 4 & 26 \\ \text { Schulze 2002 } & 35 & 79 \\ \text { Besch 2002 } & 7 & 15 \\ \text { Kankare 1998 } & 5 & 6 \\ \text { Schwarz 1997 } & 6 & 9 \\ \text { Gilquist 1974 } & 24 & 27 \\ & & \\ \text { Random effects model } & & \mathbf{2 4 6} \\ \text { Prediction interval } & & \\ \text { Heterogeneity: } I^{2}=93 \%, \tau^{2}=3.5875, p<0.01\end{array}$

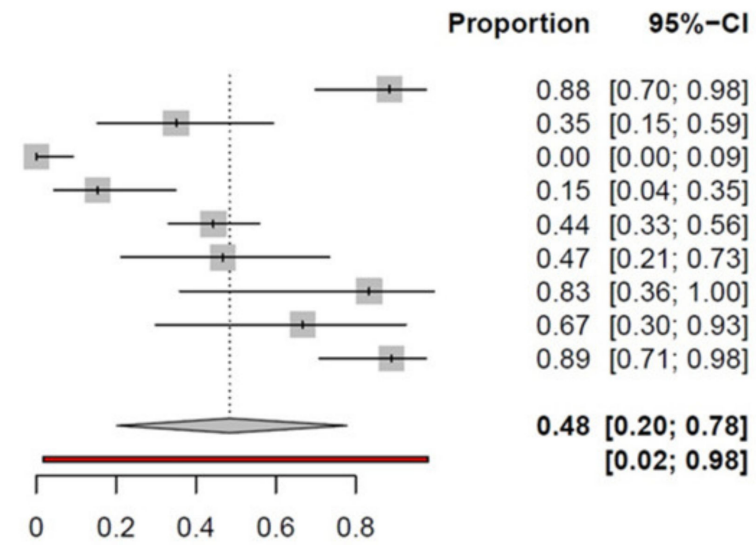

Figure 4. Forest plot illustrating the proportion meta-analysis of talar neck and body fractures; $n \mathrm{Fx}$ : number of fractures; CI: confidence interval.

In two studies [46,60], talar fractures were classified using the Szyszkowitz classification. Success rates stratified by the Szyszkowitz classification were $91 \%$ for type 1 ( $n=11$; $\left.I^{2}=0 \%\right), 77 \%$ for type $2\left(n=25 ; I^{2}=64\right), 79 \%$ for type $3\left(n=20 ; I^{2}=54 \%\right)$, and $62 \%$ for type $4\left(n=39 ; I^{2}=59 \%\right)$.

Two studies [16,59] including 13 fractures of the talar body demonstrated a success rate of $56 \%\left(I^{2}=65 \%\right)$. Schulze et al. [18] classified fractures according to Marti/Weber. Success rates stratified by the Marti/Weber talus fracture classification were $53 \%$ for type 1 $(n=15), 57 \%$ for type $2(n=14), 44 \%$ for type $3(n=32)$, and $26 \%$ for type $4(n=19)$.

Two studies $[50,54]$ reported outcomes of talar body fractures depending on fracture course. A success rate of $42 \%$ was found in five fractures with a coronal course and $31 \%$ in seven fractures with a sagittal course. The heterogeneity was negligible, with $I^{2}=17 \%$ and $I^{2}=0 \%$ for coronal and sagittal fracture courses, respectively.

\subsubsection{Complication Rate}

All 29 included studies were considered for evaluation of avascular bone necrosis $(\mathrm{AVN})$ as a complication. AVN had a prevalence of $25 \%$ in a total of 987 talus fractures, regardless of the severity of the fracture. Notably, heterogeneity was very high, with an $I^{2}$ value of $91 \%$ (Figure 5). Another subgroup analysis on talar neck fractures $(n=377)$ revealed a $43 \%$ necrosis rate $\left(I^{2}=85 \%\right)$. Nine studies reported TN/TB fractures with additional information on AVN. In this subgroup, including $n=246$ fractures, a necrosis rate of $25 \%$ was estimated $\left(I^{2}=88 \%\right)$.

Data from 17 studies investigated posttraumatic osteoarthritis (OA) following talus fractures. An OA rate of $43 \%$ was determined by analyzing $n=637$ fractures. As for AVN analysis, the $I^{2}$ value was $96 \%$, and thus indicated high heterogeneity (Figure 6). 
Study

Liu 2019

Liu 2017

Xue 2014

Chen 2014

Ohl 2011

Tang 2010

Pogliacomi 2009

Vallier 2004

Lindvall 2004

Schulze 2002

Besch 2002

Elgafy 2000

Kankare 1998

Schwarz 1997

Frawley 1995

Freund 1988

Szyszkowitz 1985

Santavirta 1984

Penny 1980

Lemaire 1980

Zifko 1979

Canale 1978

Lorentzen 1977

Peterson 1977

Sneppen 1977

Gilquist 1974

Pantazopoulos 1974

Hawkins 1970

Herwig 1967

Random effects model

Prediction interval

Heterogeneity: $I^{2}=91 \%, \tau^{2}=2.0230, p<0.01$

AVN n Fx

326

$13 \quad 21$

628

$\begin{array}{ll}38 & 44\end{array}$

$4 \quad 20$

$\begin{array}{rr}0 & 9 \\ 0 & 16\end{array}$

$10 \quad 38$

$\begin{array}{ll}7 & 26\end{array}$

$\begin{array}{ll}9 & 79\end{array}$

$\begin{array}{ll}9 & 15\end{array}$

$10 \quad 58$

06

$\begin{array}{ll}9 & 9\end{array}$

$\begin{array}{rr}4 & 26 \\ 4 & 7\end{array}$

$\begin{array}{ll}2 & 69\end{array}$

$\begin{array}{ll}0 & 35\end{array}$

$\begin{array}{ll}13 & 27\end{array}$

$\begin{array}{ll}2 & 7\end{array}$

$\begin{array}{ll}33 & 87\end{array}$

$\begin{array}{ll}37 & 71\end{array}$

$\begin{array}{ll}26 & 63\end{array}$

636

$\begin{array}{ll}8 & 51\end{array}$

$\begin{array}{ll}3 & 27\end{array}$

920

$24 \quad 44$

422

987
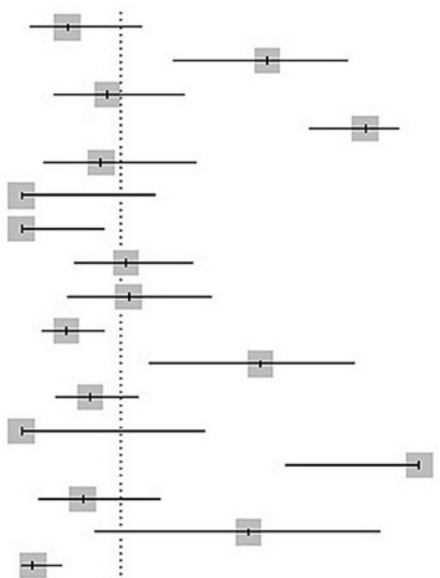

$+$

ㄴ
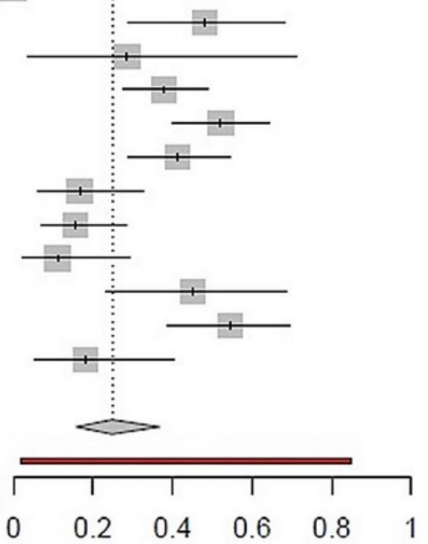

Proportion $\quad 95 \%-\mathrm{Cl}$

$0.12[0.02 ; 0.30]$

$0.62[0.38 ; 0.82]$

$0.21[0.08 ; 0.41]$

$0.86[0.73 ; 0.95]$

$0.20[0.06 ; 0.44]$

$0.00[0.00 ; 0.34]$

$0.00[0.00 ; 0.21]$

$0.26[0.13 ; 0.43]$

$0.27[0.12 ; 0.48]$

$0.11[0.05 ; 0.21]$

$0.60[0.32 ; 0.84]$

$0.17[0.09 ; 0.29]$

$0.00[0.00 ; 0.46]$

$1.00[0.66 ; 1.00]$

$0.15[0.04 ; 0.35]$

$0.57[0.18 ; 0.90]$

$0.03[0.00 ; 0.10]$

$0.00[0.00 ; 0.10]$

$0.48[0.29 ; 0.68]$

$0.29[0.04 ; 0.71]$

$0.38[0.28 ; 0.49]$

$0.52[0.40 ; 0.64]$

$0.41[0.29 ; 0.54]$

$0.17[0.06 ; 0.33]$

$0.16[0.07 ; 0.29]$

$0.11[0.02 ; 0.29]$

$0.45[0.23 ; 0.68]$

$0.55[0.39 ; 0.70]$

$0.18[0.05 ; 0.40]$

$0.25[0.16 ; 0.37]$

$[0.02 ; 0.85]$

Figure 5. Forest plot illustrating the prevalence of posttraumatic AVN following talar fractures in a proportion meta-analysis; $n \mathrm{Fx}$ : number of fractures; AVN: avascular necrosis; CI: confidence interval.

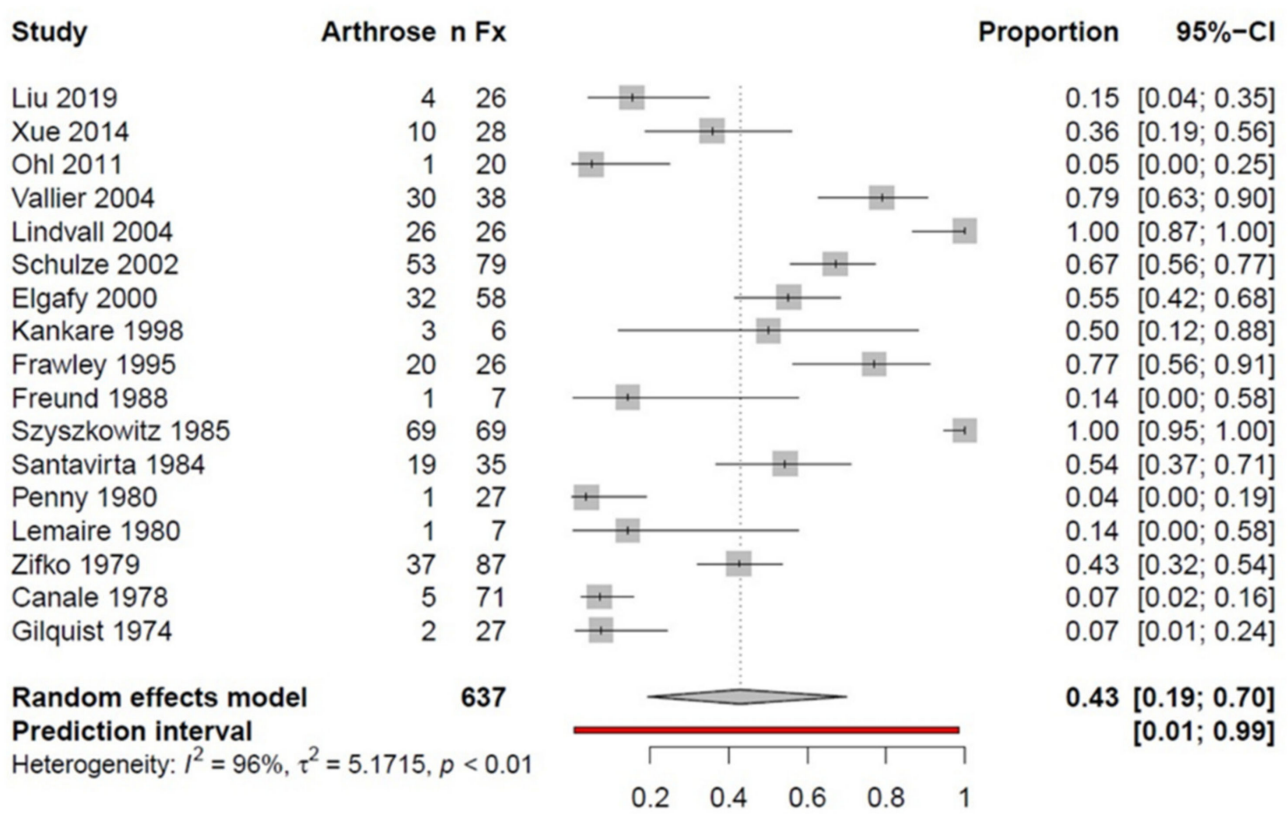

Figure 6. Forest plot illustrating the prevalence of posttraumatic osteoarthritis following talar fractures in a proportion meta-analysis; $n \mathrm{Fx}$ : number of fractures; $\mathrm{AVN}$ : avascular necrosis; $\mathrm{CI}$ : confidence interval. 


\section{Discussion}

The present systematic review and meta-analysis aimed to investigate the clinical outcomes of talar fractures, with a special focus on success as well as complications. Based on the available evidence, clinical outcomes of talar fractures were dependent on their severity, and were generally unsatisfying. We estimated a success rate of $62 \%$ for 987 fractures, regardless of the location and severity of the fracture. In 12 studies including $n=377$ fractures of the talar neck, the success rate was $60 \%$. Furthermore, the AVN rate was estimated to be $25 \%$ for pooled talar fractures, with higher rates $(43 \%)$ for talar neck fractures than talar neck and body fractures $(25 \%)$. We also found similar rates of posttraumatic osteoarthritis (43\%).

\subsection{Pooled Talar Fractures}

When pooling all talar fractures $(n=987)$ in the present meta-analysis, a success rate of $62 \%$ was found in conjunction with high heterogeneity of $I^{2}=91 \%$, questioning the reliability of the results. Comparable studies examining talar fractures are currently scarce. Halvorson et al. (2013) [33] reported a success rate of 56\% in 429 talar neck fractures. Sneppen et al. (1977) [35] estimated a 39\% success rate for 51 fractures of the talar body. Similarly, Dumont et al. (2007) [64] examined the clinical results of 41 talar fractures, and reported an average success rate of $39 \%$.

\subsection{Talar Neck Fractures}

Twelve studies were included in the evaluation of the outcome of talar neck fractures. The success rate was $60 \%$ for the 377 fractures. Halvorson et al. examined outcomes of talar neck fractures in 2013 [33]. Results from a total of 943 fractures of the talar neck were collected from 21 studies. Similar to the present meta-analysis, not all fractures could be clinically reexamined due to loss to follow-up, and remaining fractures were reexamined using a wide variety of outcome scores. Nonetheless, the authors were able to extract the clinical results of 429/943 fractures, which were examined using the Hawkins score. A success rate (i.e., excellent and good results) of $56 \%$ was demonstrated. A total of 87 patients had an excellent result, and 152 revealed good results in the follow-up examination. The results are in accordance with the results provided in the present work.

\subsection{Fracture Severity}

Several classifications have been established to determine the severity of talar fractures. Outcomes of the 29 included studies were described with eight different score systems: $11 \times$ Hawkins score [4], $6 \times$ AOFAS score [65,66], $1 \times$ Ankle-Hindfoot Scale (AHS) [66,67], $5 \times$ Maryland Score [68], $1 \times$ Foot Function Index (FFI) [66], $1 \times$ Mazur Score [68], $1 \times$ Kiel Foot Score [44], and $1 \times$ score according to Frawley [46]. All mentioned score systems share the following characteristics: they measure the outcome after talar trauma based on the range of motion, strength, functionality, stability, and pain. The Hawkins classification, modified by Canale and Kelly, is most often used for talar neck fractures. However, other classifications (including the Szyszkowitz classification and Marti/Weber) are also commonly found in the literature. A shared feature of these gradings is that they affect the treatment and prognosis of the fractures, as both depend on the severity of the fracture. In all classifications, non-dislocated fractures are considered to result in fewer complications, whereas fractures with complete dislocation or fragmented fractures are more often associated with a complicated course, as demonstrated in the present work.

In 69 fractures classified according to Hawkins 1, a success rate of $65 \%$ was found. In contrast, the success rate for nine fractures that fell into the Hawkins 4 classification was $25 \%$. The heterogeneity in this subgroup analysis lies in a range of $0-48 \%$, and can therefore be classified as insignificant to moderate. The estimation results can thus be viewed as relatively consistent. However, the number of fractures in the individual subgroups was inconsistent. In the largest group (Hawkins 2), there were 150 examined fractures. In contrast, only nine fractures were included in the Hawkins 4 fracture group. 
A similar picture emerges when focusing on the fracture outcomes classified according to Marti/Weber and Szyskowitz. In summary, despite the low number of patients in the individual groups, there is a clear tendency towards higher success rates for simple fractures versus low success rates for complex fractures.

\subsection{Complications}

All 29 inclusion studies could be included to evaluate the avascular bone necrosis (AVN) rates following talar fractures. An AVN rate of $25 \%$ was found in a total of 987 talus fractures, regardless of the severity of the fracture. In the subgroup of fractures of the talar neck $(n=377)$, the result corresponds to a $43 \%$ AVN rate. Fractures of the talar neck and body were examined in nine studies. In this subgroup with $n=246$ fractures, a necrosis rate of $25 \%$ was determined. Although there was a considerable amount of heterogeneity among these studies, the results obtained largely coincide with those provided by Dodd et al. [36]. They evaluated the data of 26 studies with a total of 980 talar neck fractures, and determined an overall AVN rate of $31 \%$. Similarly, Metzger et al. [11] reported an AVN rate of $37 \%$ in 12 studies reporting a total of 589 talar neck fractures.

Information on posttraumatic osteoarthritis was obtained from 17 studies, including 637 fractures that were identified in $43 \%$ of all cases, regardless of fracture location and /or severity. Dodd et al. [36] examined degenerative changes in the subtalar joint of 647 talar fractures. They reported a posttraumatic osteoarthritis rate of $49 \%$. This result is in accordance with the results determined in the present work. In contrast, Halvorson et al. [33] reported posttraumatic osteoarthritis rates of $68 \%$ in 635 talar neck fractures. The tibiotalar, subtalar, and talonavicular joints were affected. In some cases, multiple joints were involved at the same time. Notably, the subtalar joint was most often affected. Sanders et al. [67] examined 70 fractures of the talar neck in 69 patients and concluded that the initial functional results greatly predicted the follow-up complication rates. The incidence of secondary reconstructive surgery after talar neck fractures increased over time, and was most commonly performed to treat subtalar arthritis or malalignment after inadequate fracture healing. The calculated percentages of patients who needed secondary surgery at one, two, five, and 10 years were $24 \%, 32 \%, 38 \%$, and $48 \%$, respectively.

\subsection{Strengths and Limitations}

The present work is associated with strengths and limitations. First, the Hawkins classification [4] modified by Canale and Kelly [6] is the most common classification system for talar neck fractures $[69,70]$. Drummond Filho et al. showed that the inter- and intra-rater reliability of the Hawkins classification was generally satisfactory [71]. However, no reliability studies are currently available for the other classifications considered in the included studies. Another limitation when comparing the included studies was the variety of different outcome scores. We pooled excellent and good results to estimate success rates. Thus, the difference between the scoring systems could be partially counteracted. The two most frequently used outcome scores in the included studies were the Hawkins score and the AOFAS Ankle-Hindfoot score. As far as we know, none of these scoring systems have yet been evaluated with regards to their validity and/or reliability in patients with talar neck fractures. The AOFAS score is one of the most frequently used outcome measures in foot and ankle surgery, although it has not yet been adequately tested regarding validity or reliability. This remains a problem when assessing the outcome of foot and ankle trauma. Overall, comparing patient outcomes is difficult without reliable and standardized outcome measures [36]. Unfortunately, we found no studies comparing the scoring systems mentioned above. An in-depth analysis of the sources of heterogeneity using meta-regression techniques did not allow any meaningful conclusion. According to the Cochrane handbook, this would be defined as heterogeneity that cannot be explained [72]. Therefore, we performed a meta-analysis considering the heterogeneous character of the studies by applying a random effects model, following the recommendations of the Cochrane handbook. A random effects model, in contrast to the fixed effects model, accounts for 
statistical heterogeneity. The authors assume that the factors of the surgeon and therapy could be the most straightforward explanation, as the publications ranged from 1974-2019, and, in this time frame, the experience of the surgeons and the development of the surgical technique might have a significant influence that, however, cannot be analyzed statistically in the present study.

Furthermore, the included studies of the present work revealed a rather moderate methodological quality, with a mean CMS of 34.3 (range: 19-47). None of the included studies achieved the maximum possible number of points. Most studies reached only a few points in the categories study size, study type, and description of the postoperative rehabilitation protocol. The Coleman Methodology Score was developed by Coleman et al. to assess the methodological quality of clinical studies. Since then, the score has been used in numerous studies dealing with trauma surgery and orthopedics. In this systematic review, we applied the CMS for the first time to evaluate the methodological quality of studies focusing on talar fractures. As most included studies showed a level 4 grade of evidence, selection bias could have been a problem. However, most included studies reported that patients were consecutively included. The selection process and the handling of excluded patients are assessed in the Coleman Methodology Score in part B3. The included studies received an average of 3.5 out of a maximum of 15 possible points. Therefore, selection bias should be considered when interpreting the present results. Comparable systematic reviews on this topic were published between 2013 and 2017, but mainly focused on talar neck fractures $[33,36,73]$. The majority of the currently available reviews call for an analysis of predictive factor and subgroup evaluations to examine the reason for the high complication rates. The advantage of our initial study protocol compared to the available reviews was the focus on talar fractures generally, and not only talar neck fractures. On the one hand, this broadens understanding and allows comparability of complication rates in different talar regions within one systematic review protocol. On the other hand, we have applied a random effects model while analyzing the studies, which better accounts for the heterogeneous character of the studies compared to the current meta-analysis conducted on talar neck fractures previously [36]. A constant evaluation of the literature on this topic in the form of a systematic approach is warranted to find new and promising developments and therapeutic advances. Our literature search yielded one recent study performed by Lui et al., which generally showed lower AVN and osteoarthritis rates than those obtained by the pooled prediction in the random effects model [53]. After anatomical reduction, they used two screws and fixed the lateral malleolus with distending wires. This recent reporting indicated that internal fixation of talar fractures with lateral malleolar osteotomy might be associated with satisfying clinical outcomes. Most of the evidence included in the aforementioned systematic reviews was published in the last century, and might not be comparable to the currently performed techniques. Historically, therapy of talar fractures was generally performed more conservatively compared to the current strategies. Thus, prospective studies and literature searches should be performed in regular time intervals so as not to miss any progress on this topic that might be of relevance for the therapy of future affected patients.

\subsection{Recommendations}

Overall, the current evidence on clinical outcomes following talar fractures must be considered insufficient. To the best of our knowledge, there are no randomized controlled trials on this topic, limited to the current evidence grade. Prospective randomized and nonrandomized studies will be of help to gain more reliable evaluations of outcomes in future. A standardization of talar fracture classifications and scoring systems would improve the comparability of future studies. Large sample-sized prospective studies are warranted to detect further predictive factors influencing the currently unsatisfactory clinical outcome of patients undergoing talar fracture treatment. Specifically, the confounding factors of the surgeon and exact treatment strategy should be considered in future studies. Studies involving multiple surgeons, secondary treatments, and/or multiple treatments bias the 
result evaluations, and might be the reason for the current heterogeneity in the literature. Considering the remaining high rate of complications despite the development of diagnostics and surgical therapies, delayed surgery and remaining fracture displacements might be the main risk factors for complications. However, current reports do not call for immediate emergent surgical management using open reduction and internal fixation in contrast to historical recommendations [74]. Nevertheless, nonsurgical treatment should only be reserved for nondisplaced fractures. Nearly $95 \%$ of the talar neck fractures since 2000 were treated surgically [36]. Notably, the quality of reduction seems to be more important than the timing of reduction [75]. A dual incision technique utilizing anteromedial and anterolateral approaches for talar neck fractures under good visualization and fluoroscopy during reduction helps to prevent rotational and angular malreductions [76]. For treatment of talar neck fractures, there is no clear clinical evidence for superiority between screw fixation alone and screw/plate fixation [76]. However, screw fixation may be advantageous for maintaining the talar neck's crucial blood supply. For talar body fracture treatment, the biplanar chevron technique showed high malunion rates of up to $30 \%$ when fixed with two lag screws compared to buttress plates, whereas, for talar head fractures, a dual incision technique with medial-to-lateral screws recessed into the subchondral bone was recently introduced for fixation [77]. The following key points should be considered by orthopedic surgeons and researchers, which might help to decrease the complication rates in the future: (1) standardized treatment algorithms based on high-evidence studies; (2) standardized outcome evaluations of the applied therapies; (3) timely soft tissue coverage and management for open fractures; and (4) the quality of the surgical technique seems to be more important than the time of reduction.

\section{Conclusions}

The present meta-analysis on clinical outcomes of patients undergoing conservative or surgical treatment for talar fractures reveals a lack of reliable prospective evidence. Talar fractures are associated with relatively poor postoperative outcomes, high rates of AVN, and posttraumatic osteoarthritis. Poor outcomes revealed a positive association with fracture severity. Prospective studies investigating predictors for treatment success and/or failure are urgently needed to improve the overall quality of life and function of patients undergoing surgical treatment due to talar fractures.

Author Contributions: Conceptualization, J.Z. and R.R.; methodology, J.Z., R.R. and B.S.; validation, J.Z., R.R., N.S., H.S., G.L. and B.S.; formal analysis, R.R., J.Z., B.S. and S.Ü.; investigation, J.Z., B.S., R.R. and S.Ü.; resources, J.Z., H.S., G.L. and N.S.; data curation, R.R. and J.Z.; writing-original draft preparation, B.S., S.Ü., R.R., J.Z. and G.L.; writing-review and editing, J.Z., G.L., H.S., N.S. and R.R.; visualization, R.R., B.S. and S.Ü.; supervision, H.S., N.S. and J.Z.; project administration, J.Z.; funding acquisition, J.Z. and G.L. All authors have read and agreed to the published version of the manuscript.

Funding: This research received no external funding.

Institutional Review Board Statement: Not applicable.

Informed Consent Statement: Not applicable.

Data Availability Statement: The data that support the findings of this study are available from the corresponding author, upon reasonable request.

Acknowledgments: The article processing charge was funded by the Baden-Wuerttemberg Ministry of Science, Research and Art, and the University of Freiburg in the funding program Open Access Publishing.

Conflicts of Interest: The authors declare no conflict of interest. The funders had no role in the design of the study, in the collection, analyses, or interpretation of data, in the writing of the manuscript, or in the decision to publish the results. 


\section{References}

1. Kuner, E.H.; Lindenmaier, H.L. Zur Behandlung Der Talusfraktur. Unfallchirurgie 1983, 9, 35-40. [CrossRef]

2. Richter, M.; Zech, S. Behandlung der Talusfraktur. OP J. 2007, 23, 104-109. [CrossRef]

3. Zwipp, H.; Rammelt, S. Posttraumatische Korrekturoperationen am Fuß. Zent. Chir 2003, 128, 218-226. [CrossRef]

4. Hawkins, L.G. Fractures of the Neck of the Talus. J. Bone Jt. Surg. Am. 1970, 52, 991-1002. [CrossRef]

5. Zwipp, H. Chirurgie des Fußes; Springer: Vienna, Hungary, 1994; ISBN 978-3-7091-7366-4.

6. Canale, S.T.; Kelly, F.B. Fractures of the Neck of the Talus. Long-Term Evaluation of Seventy-One Cases. J. Bone Jt. Surg. Am. 1978, 60, 143-156. [CrossRef]

7. Pennal, G.F. Fractures of the Talus. Clin. Orthop. Relat. Res. 1963, 30, 53-63. [CrossRef] [PubMed]

8. Berndt, A.L.; Harty, M. Transchondral Fractures (Osteochondritis Dissecans) of the Talus. J. Bone Jt. Surg. Am. 1959, 41-A, 988-1020. [CrossRef]

9. Gregory, P.; DiPasquale, T.; Herscovici, D.; Sanders, R. Ipsilateral Fractures of the Talus and Calcaneus. Foot Ankle Int. 1996, 17, 701-705. [CrossRef]

10. Sanders, D.W.; Busam, M.; Hattwick, E.; Edwards, J.R.; McAndrew, M.P.; Johnson, K.D. Functional Outcomes Following Displaced Talar Neck Fractures. J. Orthop. Trauma 2004, 18, 265-270. [CrossRef]

11. Metzger, M.J.; Levin, J.S.; Clancy, J.T. Talar Neck Fractures and Rates of Avascular Necrosis. J. Foot Ankle Surg. 1999, 38, 154-162. [CrossRef]

12. Rammelt, S.; Zwipp, H. Talar Neck and Body Fractures. Injury 2009, 40, 120-135. [CrossRef]

13. Isay, M.; Wolvius, R.; Ochsner, P.E. Long-term results of talus fractures. Z Unf. Versicher. 1992, 85, 12-18.

14. Adelaar, R.S. The Treatment of Complex Fractures of the Talus. Orthop. Clin. N. Am. 1989, 20, 691-707.

15. Tscherne, H. Major Fractures of the Pilon, the Talus, and the Calcaneus Current Concepts of Treatment; Springer: Berlin, Germany, 1993; ISBN 978-3-642-77729-5.

16. Lindvall, E.; Haidukewych, G.; DiPasquale, T.; Herscovici, D.; Sanders, R. Open Reduction and Stable Fixation of Isolated, Displaced Talar Neck and Body Fractures. J. Bone Jt. Surg. Am. 2004, 86, 2229-2234. [CrossRef]

17. Vallier, H.A.; Nork, S.E.; Benirschke, S.K.; Sangeorzan, B.J. Surgical Treatment of Talar Body Fractures. J. Bone Jt. Surg. Am. 2004, 86- $A$ Suppl. 1, 180-192. [CrossRef]

18. Schulze, W.; Richter, J.; Russe, O.; Ingelfinger, P.; Muhr, G. Surgical Treatment of Talus Fractures: A Retrospective Study of 80 Cases Followed for 1-15 Years. Acta Orthop. Scand. 2002, 73, 344-351. [CrossRef] [PubMed]

19. Kundel, K.; Braun, W.; Scherer, A. Late results of central talus injuries. Unfallchirurg 1995, 98, 124-129. [PubMed]

20. Daniels, T.R.; Smith, J.W.; Ross, T.I. Varus Malalignment of the Talar Neck. Its Effect on the Position of the Foot and on Subtalar Motion. J. Bone Jt. Surg. Am. 1996, 78, 1559-1567. [CrossRef]

21. Rammelt, S.; Winkler, J.; Grass, R.; Zwipp, H. Reconstruction after Talar Fractures. Foot Ankle Clin. 2006, 11, 61-84. [CrossRef] [PubMed]

22. Sangeorzan, B.J.; Wagner, U.A.; Harrington, R.M.; Tencer, A.F. Contact Characteristics of the Subtalar Joint: The Effect of Talar Neck Misalignment. J. Orthop. Res. 1992, 10, 544-551. [CrossRef] [PubMed]

23. Elgafy, H.; Ebraheim, N.A.; Tile, M.; Stephen, D.; Kase, J. Fractures of the Talus: Experience of Two Level 1 Trauma Centers. Foot Ankle Int. 2000, 21, 1023-1029. [CrossRef] [PubMed]

24. Rammelt, S.; Grass, R.; Brenner, P.; Zwipp, H. Septische Talusnekrose nach drittgradig offener Talusfraktur im Rahmen eines komplexen Fußtraumas (floating talus). Trauma Berufskrankh 2001, 3, S230-S235. [CrossRef]

25. Rzesacz, E.H.; Culemann, U.; Illgner, A.; Reilmann, H. Der Homologe Talusersatz Nach Talektomie Bei Infekt Und Septischer Talusnekrose. Der. Unf. 1997, 100, 497-501. [CrossRef] [PubMed]

26. Dunn, A.R.; Jacobs, B.; Campbell, R.D. Fractures of the Talus. J. Trauma 1966, 6, 443-468. [CrossRef] [PubMed]

27. Kenwright, J.; Taylor, R.G. Major injuries of the talus. J. Bone Jt. Surgery Br. Vol. 1970, 52-B, 36-48. [CrossRef]

28. Lorentzen, J.E.; Christensen, S.B.; Krogsoe, O.; Sneppen, O. Fractures of the Neck of the Talus. Acta Orthop. Scand. 1977, 48, 115-120. [CrossRef]

29. Penny, J.N.; Davis, L.A. Fractures and Fracture-Dislocations of the Neck of the Talus. J. Trauma 1980, 20, 1029-1037. [CrossRef]

30. Baumhauer, J.F.; Alvarez, R.G. Controversies in Treating Talus Fractures. Orthop. Clin. N. Am. 1995, 26, 335-351. [CrossRef]

31. Fortin, P.T.; Balazsy, J.E. Talus Fractures: Evaluation and Treatment. J. Am. Acad. Orthop. Surg. 2001, 9, 114-127. [CrossRef]

32. Wirth, C.J. Fuß; Georg Thieme Verlag: Stuttgart, Germany, 2002; ISBN 978-3-13-126241-7.

33. Halvorson, J.J.; Winter, S.B.; Teasdall, R.D.; Scott, A.T. Talar Neck Fractures: A Systematic Review of the Literature. J. Foot Ankle Surg. 2013, 52, 56-61. [CrossRef]

34. Patel, R.; Van Bergeyk, A.; Pinney, S. Are Displaced Talar Neck Fractures Surgical Emergencies? A Survey of Orthopaedic Trauma Experts. Foot Ankle Int. 2005, 26, 378-381. [CrossRef]

35. Sneppen, O.; Christensen, S.B.; Krogsoe, O.; Lorentzen, J. Fracture of the Body of the Talus. Acta Orthop. Scand. 1977, 48, 317-324. [CrossRef]

36. Dodd, A.; Lefaivre, K.A. Outcomes of Talar Neck Fractures: A Systematic Review and Meta-Analysis. J. Orthop. Trauma 2015, 29, 210-215. [CrossRef]

37. Leonetti, D.; Di Matteo, B.; Barca, P.; Cialdella, S.; Traina, F.; Arcidiacono, M.; Kon, E.; Tigani, D. Complications after Displaced Talar Neck Fracture: Results from a Case Series and a Critical Review of Literature. TOORTHJ 2018, 12, 567-575. [CrossRef] 
38. Ibrahim, M.S.; Jordan, R.; Lotfi, N.; Chapman, A.W.P. Talar Head Fracture: A Case Report, Systematic Review and Suggested Algorithm of Treatment. Foot 2015, 25, 258-264. [CrossRef] [PubMed]

39. PRISMA-P Group; Mohar, D.; Shamseer, L.; Clarke, M.; Ghersi, D.; Liberati, A.; Petticrew, M.; Shekelle, P.; Stewart, L.A. Preferred Reporting Items for Systematic Review and Meta-Analysis Protocols (PRISMA-P) 2015 Statement. Syst. Rev. 2015, 4, 1. [CrossRef]

40. Coleman, B.D.; Khan, K.M.; Maffulli, N.; Cook, J.L.; Wark, J.D. Studies of Surgical Outcome after Patellar Tendinopathy: Clinical Significance of Methodological Deficiencies and Guidelines for Future Studies. Victorian Institute of Sport Tendon Study Group. Scand. J. Med. Sci. Sports 2000, 10, 2-11. [CrossRef] [PubMed]

41. Wright, J.G.; Swiontkowski, M.F.; Heckman, J.D. Introducing Levels of Evidence to the Journal. J. Bone Jt. Surg. Am. 2003, 85, 1-3. [CrossRef]

42. Higgins, J.P.T.; Thompson, S.G. Quantifying Heterogeneity in a Meta-Analysis. Stat. Med. 2002, 21, 1539-1558. [CrossRef]

43. Schwarzer, G.; Chemaitelly, H.; Abu-Raddad, L.J.; Rücker, G. Seriously Misleading Results Using Inverse of Freeman-Tukey Double Arcsine Transformation in Meta-Analysis of Single Proportions. Res. Synth. Methods 2019, 10, 476-483. [CrossRef]

44. Besch, L.; Drost, J.; Egbers, H.-J. Die Behandlung der seltenen Talusluxationsfrakturen Analyse von 23 Verletzungen: Analyse von 23 Verletzungen. Unfallchirurg 2002, 105, 595-601. [CrossRef] [PubMed]

45. Chen, H.; Liu, W.; Deng, L.; Song, W. The Prognostic Value of the Hawkins Sign and Diagnostic Value of MRI after Talar Neck Fractures. Foot Ankle Int. 2014, 35, 1255-1261. [CrossRef] [PubMed]

46. Frawley, P.A.; Hart, J.A.L.; Young, D.A. Treatment Outcome of Major Fractures of the Talus. Foot Ankle Int. 1995, 16, 339-345. [CrossRef] [PubMed]

47. Freund, K.G. Complicated Fractures of the Neck of the Talus. Foot Ankle 1988, 8, 203-207. [CrossRef]

48. Gilquist, J.; Oretop, N.; Stenström, A.; Rieger, A.; Wennberg, E. Late Results after Vertical Fracture of the Talus. Injury 1974, 6, 173-179. [CrossRef]

49. Herwig, K. Treatment results of fresh talus fractures. Z Unf. Berufskr 1967, 60, 91-106.

50. Kankare, J.; Rokkanen, P. Dislocated Fractures of the Talus Treated with Biodegradable Internal Fixation. Arch Orthop. Trauma Surg. 1998, 117, 62-64. [CrossRef]

51. Lemaire, R.G.; Bustin, W. Screw Fixation of Fractures of the Neck of the Talus Using a Posterior Approach. J. Trauma 1980, 20, 669-673. [CrossRef] [PubMed]

52. Liu, H.; Chen, Z.; Zeng, W.; Xiong, Y.; Lin, Y.; Zhong, H.; Wu, J. Surgical Management of Hawkins Type III Talar Neck Fracture through the Approach of Medial Malleolar Osteotomy and Mini-Plate for Fixation. J. Orthop. Surg. Res. 2017, 12, 111. [CrossRef] [PubMed]

53. Liu, G.; Ge, J.; Zheng, X.; Wu, C.; Yan, Q.; Yang, H.; Zou, J. Therapeutic Efficacy Analysis of Talar Fracture Internal Fixation with Lateral Malleolar Osteotomy. Med. Sci. Monit. 2019, 25, 3463-3468. [CrossRef]

54. Ohl, X.; Harisboure, A.; Hemery, X.; Dehoux, E. Long-Term Follow-up after Surgical Treatment of Talar Fractures: Twenty Cases with an Average Follow-up of 7.5 Years. Int. Orthop. 2011, 35, 93-99. [CrossRef] [PubMed]

55. Pantazopoulos, T.; Galanos, P.; Vayanos, E.; Mitsou, A.; Hartofilakidis-Garofalidis, G. Fractures of the Neck of the Talus. Acta Orthop. Scand. 1974, 45, 296-306. [CrossRef]

56. Peterson, L.; Goldie, I.F.; Irstam, L. Fracture of the Neck of the Talus. A Clinical Study. Acta Orthop. Scand. 1977, 48, 696-706. [CrossRef]

57. Pogliacomi, F.; De Filippo, M.; Soncini, G.; Frattini, M. Talar Fractures: Long-Term Results. Acta Biomed. 2009, 80, 219-224. [PubMed]

58. Santavirta, S.; Seitsalo, S.; Kiviluoto, O.; Myllynen, P. Fractures of the Talus. J. Trauma 1984, 24, 986-989. [CrossRef]

59. Schwarz, N.; Eschberger, J.; Kramer, J.; Posch, E. Radiologische Und Histologische Beobachtungen an Zentralen Talusfrakturen. Der. Unf. 1997, 100, 449-456. [CrossRef]

60. Szyszkowitz, R.; Reschauer, R.; Seggl, W. Eighty-Five Talus Fractures Treated by ORIF with Five to Eight Years of Follow-up Study of 69 Patients. Clin. Orthop. Relat. Res. 1985, 199, 97-107. [CrossRef]

61. Tang, H.; Han, K.; Li, M.; Zhang, Q.; Xie, Y.; Tang, X.; Xu, H.; Mao, N. Treatment of Hawkins Type II Fractures of Talar Neck by a Vascularized Cuboid Pedicle Bone Graft and Combined Internal and External Fixation: A Preliminary Report on Nine Cases. J. Trauma 2010, 69, E1-E5. [CrossRef]

62. Xue, Y.; Zhang, H.; Pei, F.; Tu, C.; Song, Y.; Fang, Y.; Liu, L. Treatment of Displaced Talar Neck Fractures Using Delayed Procedures of Plate Fixation through Dual Approaches. Int. Orthop. 2014, 38, 149-154. [CrossRef] [PubMed]

63. Zifko, B.; Wittich, H. Classification and treatment results of various types of talus fractures. Hefte Unf. 1979, 134, 14-24.

64. Dumont, C.; Fuchs, M.; Burchhardt, H.; Tezval, M.; Wachowski, M.; Stürmer, K. Wie sind die klinischen Ergebnisse operativ behandelter Talusfrakturen? Z Orthop Unf. 2007, 145, 212-220. [CrossRef] [PubMed]

65. Kostuj, T.; Schaper, K.; Baums, M.N.; Lieske, S. Eine Validierung des AOFAS-Ankle-Hindfoot-Scale für den deutschen Sprachraum. Fuß Sprunggelenk 2014, 12, 100-106. [CrossRef]

66. Madeley, N.J.; Wing, K.J.; Topliss, C.; Penner, M.J.; Glazebrook, M.A.; Younger, A.S. Responsiveness and Validity of the SF-36, Ankle Osteoarthritis Scale, AOFAS Ankle Hindfoot Score, and Foot Function Index in End Stage Ankle Arthritis. Foot Ankle Int. 2012, 33, 57-63. [CrossRef] [PubMed]

67. Sanders, R.; Fortin, P.; DiPasquale, T.; Walling, A. Operative Treatment in 120 Displaced Intraarticular Calcaneal Fractures. Results Using a Prognostic Computed Tomography Scan Classification. Clin. Orthop. Relat. Res. 1993, 290, 87-95. 
68. Mazur, J.M.; Schwartz, E.; Simon, S.R. Ankle Arthrodesis. Long-Term Follow-up with Gait Analysis. J. Bone Jt. Surg. Am. 1979, 61, 964-975. [CrossRef]

69. Alton, T.; Patton, D.J.; Gee, A.O. Classifications in Brief: The Hawkins Classification for Talus Fractures. Clin. Orthop. Relat. Res. 2015, 473, 3046-3049. [CrossRef]

70. Williams, T.; Barba, N.; Noailles, T.; Steiger, V.; Pineau, V.; Carvalhana, G.; Le Jacques, B.; Clave, A.; Huten, D. Total Talar Fracture-Inter-and Intra-Observer Reproducibility of Two Classification Systems (Hawkins and AO) for Central Talar Fractures. Orthop. Traumatol. Surg. Res. 2012, 98, S56-65. [CrossRef] [PubMed]

71. Drummond Filho, M.L.; Verzani, M.A.; Rosa, A.F.; Pimenta, C.J.; Grynwald, J.; Cliquet Junior, A. Fractures of the Neck of the Talus: Evaluation of Reproducibility of Hawkins' Classification. Acta Ortop. Bras. 2012, 20, 170-173. [CrossRef] [PubMed]

72. Higgins, J.; Green, S. Cochrane Handbook for Systematic Reviews of Interventions Version 5.1.0; The Cochrane Collaboration, John Wiley \& Sons: Hoboken, NJ, USA, 2011.

73. Jordan, R.K.; Bafna, K.R.; Liu, J.; Ebraheim, N.A. Complications of Talar Neck Fractures by Hawkins Classification: A Systematic Review. J. Foot Ankle Surg. 2017, 56, 817-821. [CrossRef]

74. Biz, C.; Golin, N.; De Cicco, M.; Maschio, N.; Fantoni, I.; Frizziero, A.; Belluzzi, E.; Ruggieri, P. Long-Term Radiographic and Clinical-Functional Outcomes of Isolated, Displaced, Closed Talar Neck and Body Fractures Treated by ORIF: The Timing of Surgical Management. BMC Musculoskelet. Disord. 2019, 20, 363. [CrossRef] [PubMed]

75. Buckwalter, V.J.A.; Westermann, R.; Mooers, B.; Karam, M.; Wolf, B. Timing of Surgical Reduction and Stabilization of Talus Fracture-Dislocations. Am. J. Orthop. 2017, 46, E408-E413.

76. Lee, C.; Brodke, D.; Perdue, P.W.; Patel, T. Talus Fractures: Evaluation and Treatment. J. Am. Acad. Orthop. Surg. 2020, 28, e878-e887. [CrossRef] [PubMed]

77. Bull, P.E.; Berlet, G.C.; Canini, C.; Hyer, C.F. Rate of Malunion Following Bi-Plane Chevron Medial Malleolar Osteotomy. Foot Ankle Int. 2016, 37, 620-626. [CrossRef] [PubMed] 